University of Nebraska - Lincoln

DigitalCommons@University of Nebraska - Lincoln

\title{
Fast Growth of Thin MAPbl 3 Crystal Wafers on Aqueous Solution Surface for Efficient Lateral-Structure Perovskite Solar Cells
}

\author{
Ye Liu \\ University of Nebraska-Lincoln \\ Qingfeng Dong \\ University of Nebraska-Lincoln, qingfeng.dong@gmail.com \\ Yanjun Fang \\ University of Nebraska-Lincoln, jkfang@zju.edu.cn \\ Yuze Lin \\ University of North Carolina Chapel Hill \\ Yehao Deng \\ University of North Carolina Chapel Hill \\ See next page for additional authors \\ Follow this and additional works at: https://digitalcommons.unl.edu/mechengfacpub \\ Part of the Electrical and Computer Engineering Commons, Mechanics of Materials Commons, \\ Nanoscience and Nanotechnology Commons, Other Engineering Science and Materials Commons, and \\ the Other Mechanical Engineering Commons
}

Liu, Ye; Dong, Qingfeng; Fang, Yanjun; Lin, Yuze; Deng, Yehao; and Huang, Jinsong, "Fast Growth of Thin $\mathrm{MAPb}_{3}$ Crystal Wafers on Aqueous Solution Surface for Efficient Lateral-Structure Perovskite Solar Cells" (2019). Mechanical \& Materials Engineering Faculty Publications. 344.

https://digitalcommons.unl.edu/mechengfacpub/344

This Article is brought to you for free and open access by the Mechanical \& Materials Engineering, Department of at DigitalCommons@University of Nebraska - Lincoln. It has been accepted for inclusion in Mechanical \& Materials Engineering Faculty Publications by an authorized administrator of DigitalCommons@University of Nebraska Lincoln. 


\section{Authors}

Ye Liu, Qingfeng Dong, Yanjun Fang, Yuze Lin, Yehao Deng, and Jinsong Huang 


\title{
Fast Growth of Thin $\mathrm{MAPbl}_{3}$ Crystal Wafers on Aqueous Solution Surface for Efficient Lateral-Structure Perovskite Solar Cells
}

\section{Ye Liu, Qingfeng Dong, Yanjun Fang, Yuze Lin, Yehao Deng, and Jinsong Huang}

\author{
Y. Liu, Prof. Q. Dong, Prof. Y. Fang, Prof. J. Huang \\ Department of Mechanical and Materials Engineering \\ University of Nebraska-Lincoln Lincoln, NE 68588, USA \\ Dr. Y. Lin, Y. Deng, Prof. J. Huang \\ Department of Applied Physical Sciences \\ University of North Carolina Chapel Hill, NC 27599, USA \\ Corresponding author — J. Huang, jhuang@unc.edu
}

ORCID: Ye Liu 0000-0002-5415-1686; Jinsong Huang 0000-0002-0509-8778

\begin{abstract}
Solar-grade single or multiple crystalline wafers are needed in large quantities in the solar cell industry, and are generally formed by a top-down process from crystal ingots, which causes a significant waste of materials and energy during slicing, polishing, and other processing. Here, a bottom-up technique that allows the growth of wafer-size hybrid perovskite multiple crystals directly from aqueous solution is reported. Single-crystalline hybrid perovskite wafers with centimeter size are grown at the top surface of a perovskite precursor solution. As well as saving raw materials, this method provides unprecedented advantages such as easily tunable thickness and rapid growth of the crystals. These crystalline wafers show high crystallinity, broader light absorption, and a long carrier recombination lifetime, comparable with those of bulk single crystals. Lateral-structure perovskite solar cells made of these crystals demonstrate a record power conversion efficiency of $5.9 \%$.
\end{abstract}

Keywords: aqueous solution, crystal wafer, fast growth, lateral structure, perovskite solar cells 


\section{Introduction}

Organic-inorganic halide perovskite (OIHP), as a very competitive candidate of photovoltaic material, has drawn intense attention in recent years, and the growth of large-size perovskite single crystals has attracted much interest for the investigation of their intrinsic properties and device performance of OIHP. [1,2] Single crystals have much longer carrier diffusion length $[3,4]$ and lower trap density [5] than polycrystalline thin films which predict a large potential for further enhancing the performance of perovskite solar cells. [1,6-8] In past decades, silicon-based photovoltaics have been the dominating commercial solar cells, which are the most widely used renewable energy source converting solar light into electricity. Most recently, the efficiency of single-crystal silicon solar cells has reached a record of $26 \%$ for devices using the heterojunction-interdigitated back contact ( $\mathrm{HJ}$-IBC) structure, in which all electrodes are patterned at the back side of the devices in a lateral structure so that there is no loss of light from electrode shadowing. [9] The HJ-IBC structure devices could have not only higher efficiency upper limit but also reduced material cost by eliminating expensive transparent electrodes compared with regular devices. Unfortunately, there are less than a hand of studies on the perovskite materials for lateral-structure single-crystal solar cells. [10]

In order to make perovskite crystals have an impact with this HJ-IBC structure, the crystals need to be easily formed at wafer-scale for large-area devices, and the crystal thickness should be thinner than the carrier diffusion length to achieve back contact with the benefit of material saving. [11] For the growth of hybrid perovskite single crystals, there are mainly three methods reported so far: antisolvent vapor-assisted crystallization, [5] solution supersaturating at reduced temperature, $[4,12-14]$ and inverse solubility crystallization. [2,12,15-22] However, none of the current techniques for growing perovskite single crystals could make wafer-size perovskite crystals with thickness comparable to charge diffusion length. Some recent efforts have been devoted to reduce the thickness of $\mathrm{CH}_{3} \mathrm{NH}_{3} \mathrm{PbBr}_{3}\left(\mathrm{MAPbBr}_{3}\right)$ single crystals to micrometers using space-confined method, [19,22-24] however most of these thin crystals have lateral size less than $1 \mathrm{~mm}$, making them not viable for solar cell application. The lateral size in space-confinement method is mainly limited by the difficulty of precursor ion diffusion in micrometer size channel to supply enough material for crystal growth. We addressed this issue using hydrophobic polymer-covered substrates to accelerate the solution and ion diffusion along in plane direction, resulting in millimeter size single crystals. [2] Nevertheless, the slow growth of such crystals makes them not applicable for large area solar cell application. Thus, a fast growth of thin perovskite single crystal at wafer-size is required to make lateral-structure perovskite solar cells viable. 
Here, we report a low-temperature solution method to grow thin $\mathrm{CH}_{3} \mathrm{NH}_{3} \mathrm{Pbl}_{3}\left(\mathrm{MAPbl}_{3}\right)$ multicrystals with thickness down to micrometers and lateral size in centimeters within 30 min, which is a fast and scalable bottom-up technique. Here, multicrystal refers that the lateral size of crystals is larger than $1 \mathrm{~mm}$, which is thousands time larger than film thickness. Compared to polycrystalline films with grain size of micrometers or less, the grain boundary area in multicrystals is approaching that of single crystals, and thus does not have significant impact of device efficiency. The growth of the crystal is driven by the supersaturation of precursor solution caused by solvent evaporation from the solution top surface. Co-planar perovskite solar cells based on centimeter-scale multicrystalline wafers have a power conversion efficiency (PCE) of 5.9\% at room temperature, which is the highest PCE reported for lateral-structure perovskite solar cells. [25,26]

\section{Results and Discussion}

Perovskite multicrystal wafers were grown with a supersaturation process at reduced temperature on the surface of an aqueous precursor solution. Here, a more environment-benign aqueous solution was chosen for crystal growth instead of the commonly used organic solvents like $N, N$-dimethylformamide and $\gamma$-butyrolactone. Specifically, the precursor solution was preheated with a temperature of $90^{\circ} \mathrm{C}$ on hotplate, and stirred inside a beaker with fully covered top to obtain a uniformly undersaturated precursor solution in a closed space before growth. For the beginning of crystal growth, the stirrer was stopped and two pieces of glasses with a controllable gap distance were applied on top of the beaker to adjust the evaporation rate of water to effectively control the growth speed both in the nucleation process and crystal growth process. The scheme for the growth mechanism of the multicrystalline perovskite $\mathrm{MAPbl}_{3}$ wafers is shown in Figure 1a,b which can be divided into two major steps. The first stage is mainly the nucleation process to form tiny multicrystals at the center of the solution surface. The nucleation process would prefer to start at the supersaturated area near the top solution surface where water evaporates. Several nuclei would start to form and always first at the center area of the solution top surface, maybe due to the solution surface tension or the faster evaporation of water at the center. Then the outer side of each nuclei will continue to grow larger toward the outside and then the inner side will merge with each other toward the solution center which results in the formation of large multicrystals at the center of the solution. This step would always take about 5-10 min to form the multicrystals as less as possible. The second stage is the expansion of crystals outside edges from center to peripheral area on the solution surface. With the enduring solvent evaporation from the remained 
(a) Evaporation

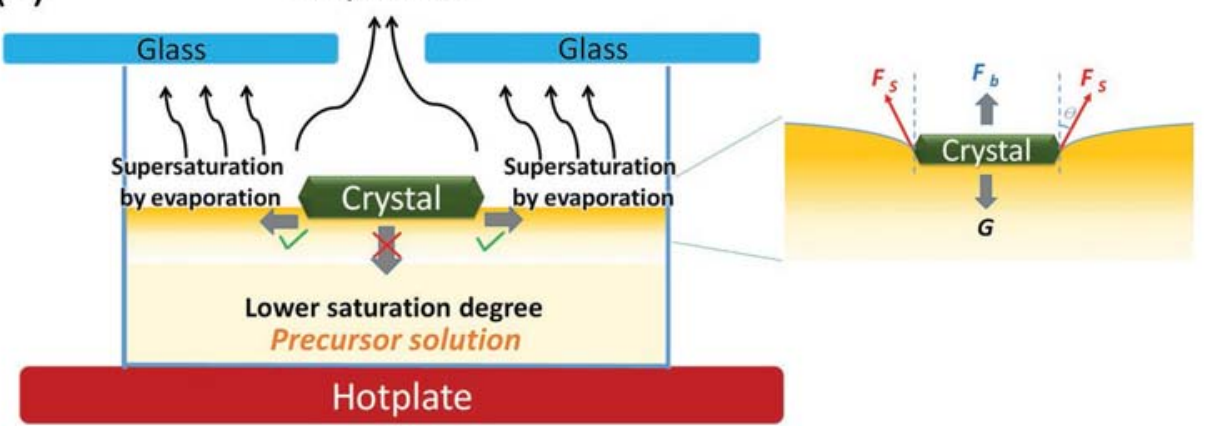

(b)
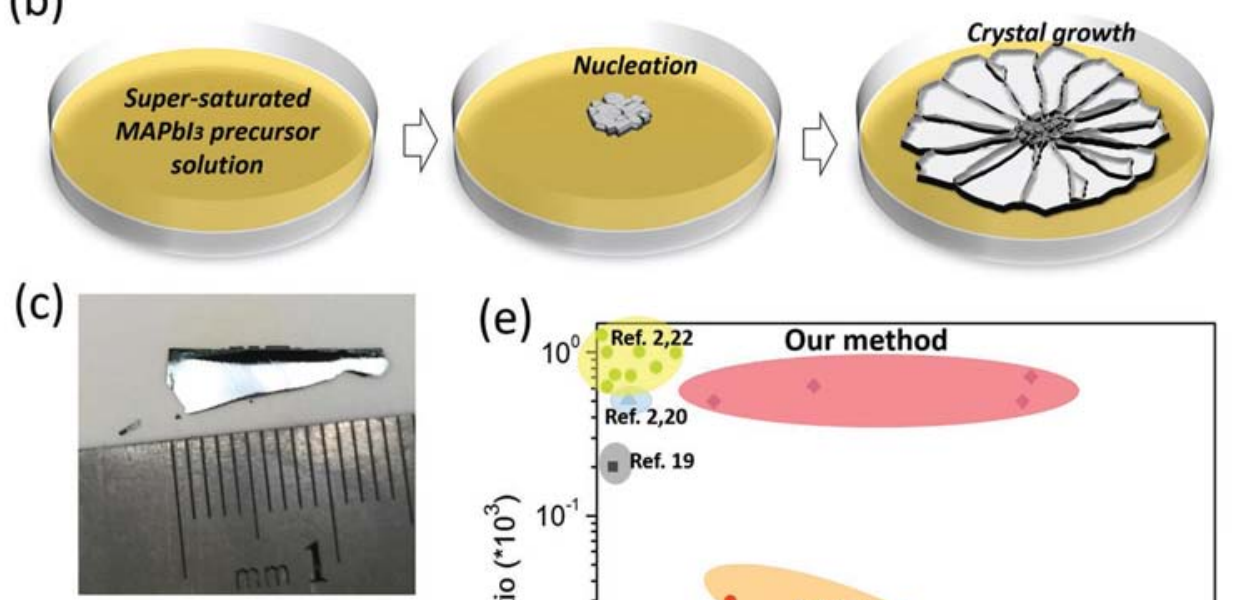

(d)
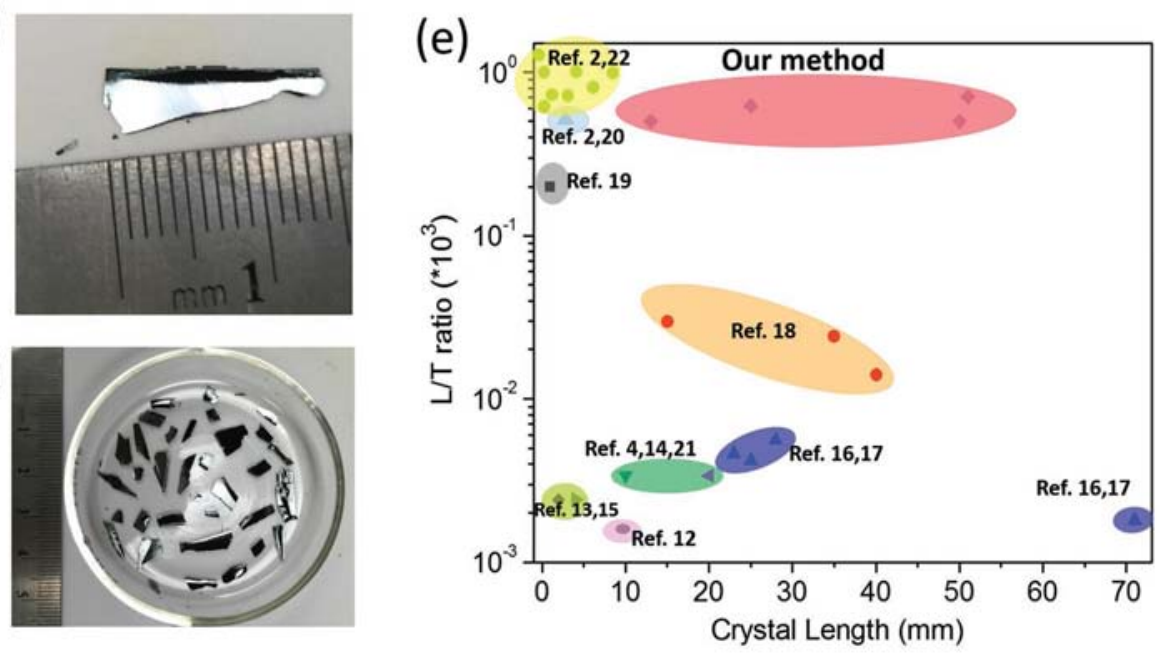

Figure 1. a,b) Scheme of crystal growth mechanism. c, d) Photograph of $1.5 \mathrm{~cm}$ length $\mathrm{MAPbl}_{3}$ single crystal piece of wafer grown from $5 \mathrm{~cm}$ diameter container. e) The comparison plot of recent $\mathrm{MAPbl}_{3}$ or $\mathrm{MAPbBr}_{3}$ single-crystal growth studies in $L / T$ ratio $\left({ }^{*} 10^{3}\right)$ versus crystal length based on the reported data.

exposed solution surface at the peripheral area, the crystals will grow from the center to the edge along the lateral direction and eventually cover the whole surface of the solution, as shown in Figure $1 \mathrm{~b}$. The multicrystals would form and float on the solution surface due to the forces provided by buoyancy $\left(F_{\mathrm{b}}\right)$ and surface tension $\left(F_{\mathrm{s}}\right)$ to balance the gravity, and the scheme of forces in equilibrium state is shown in Figure 1a. For the $100 \mathrm{~mL}$ beaker as 
container to grow, the second stage would need about 15 min at most until the grown crystals cover the whole solution surface $(5 \mathrm{~cm}$ in diameter). The size of crystals grown at the later stage is much larger compared to the first stage due to the absence of additional nucleation. The photograph of single crystals generated at the second stage is shown in Figure 1c, which shows a reflective surface. The largest crystal is $1.5 \mathrm{~cm}$ in length and tens of micrometer in thickness (Figure 1c,d).

In contrast to the previously reported methods that require days $[4,14]$ or weeks [12] to grow centimeter size single crystals with growth speed of smaller than $0.13 \mathrm{~cm} \mathrm{~h}^{-1},[4,12-18,21]$ this method has a much faster growth speed of $3.0 \mathrm{~cm} \mathrm{~h}^{-1}$ along the solution surface direction. Because of the strong driven force by solvent, evaporation was introduced to dramatically accelerate the crystals growth speed for wafer-scale crystals on top of solution surface. With the evaporation of solvent, the saturation gradient formed near the surface of the precursor solution and the top solution became supersaturated. For the two typical methods of inverse temperature crystallization and solution temperature lowering, the saturation of the whole solution inside container would be changing much uniformly by controlling temperature combined with solubility. However, in this method, the solubility of $\mathrm{MAPbl}_{3}$ on the solution top surface could be tremendously reduced from the solution under surface, which is partially over-saturated only near the solution surface. The crystal thickness could be controlled by the exposure area(gap distance) between cover glasses, solution height(distance from solution surface to the bottom), and bottom temperature, as shown in Figure 1a. If the gap distance between the two cover glass increased from 2 to $4 \mathrm{~mm}$, the crystal thickness would decrease from 35 to $20 \mu \mathrm{m}$, using a $100 \mathrm{~mL}$ beaker with the solution surface height of $3 \mathrm{~cm}$ at $90^{\circ} \mathrm{C}$ (hotplate). If we add more solution to increase the height of solution from 3 to $5 \mathrm{~cm}$ and keep the cover glass gap with $2 \mathrm{~mm}$, the crystal thickness may increase from 35 to $45 \mu \mathrm{m}$; then if we increase the temperature of bottom hotplate from 90 to $100{ }^{\circ} \mathrm{C}$, then the thickness of crystal may decrease from 45 to 30 $\mu \mathrm{m}$. The saturation gradient is in a large difference from the area near top surface of solution, and the crystal growth would prefer to grow in a rapid speed in the lateral direction. By using this growth mechanism, larger single crystals could be simply got by enlarging the lateral size of solution container, as indicated by the correlation between crystal size and container size shown in Figure S1 in the Supporting Information. The crystal lateral size $(L)$ and lateral-size-to-thickness ratio $(L / T)$ of the previously reported $\mathrm{MAPbl}_{3}$ or $\mathrm{MAPbBr}_{3}$ single crystals are summarized in Figure 1e, which indicates $\mathrm{MAPbl}_{3}$ or $\mathrm{MAPbBr}_{3}$ crystals grown by our method show a remarkably higher $L / T$ ratio and larger crystal size. The reported crystals grown with lower $L / T$ ratio below $10^{-2}\left({ }^{*} 10^{3}\right)$ were bulk single crystals, which could not get a relatively 
thin single crystal. For the crystals reported in higher $L / T$ ratio with low crystal length size $L$, they could be grown into thin as hundreds of micrometers, while the crystal lateral size was limited below $1 \mathrm{~cm}$. Thus, our method could not only in high $L / T$ ratio, but also large crystal size (length).

We used X-ray diffraction (XRD) measurement with 2D area detector equipped to study the crystalline quality of the MAPbI3 wafer piece in area of $5 \mathrm{~mm} \times 4 \mathrm{~mm}$, and the diameter of X-ray beam is about $1 \mathrm{~mm}$. Only one single diffraction spot was observed in the 2D diffraction image (Figure 2a), indicating the single-crystal nature of the crystal measured. The high crystallinity of the crystal was demonstrated by the very sharp (220)/(004) diffraction peak with full width at half-maximum (FWHM) as small as $0.06^{\circ}$, which is comparable with the reported FWHM of $0.07^{\circ}$. [18] From the photograph shown in Figure $1 c, d$, the surface of crystal wafer is very reflective and flat in centimeter-scale. Furthermore, the typical scanning electron microscopy (SEM) images of the top surface and cross-section of the as-grown single crystals are shown in Figure $2 c-e$ where in micrometer-scale the flat surface and sharp edge were also obviously observed with no visible grain boundaries, which could further confirm the high morphological quality of these single crystals.
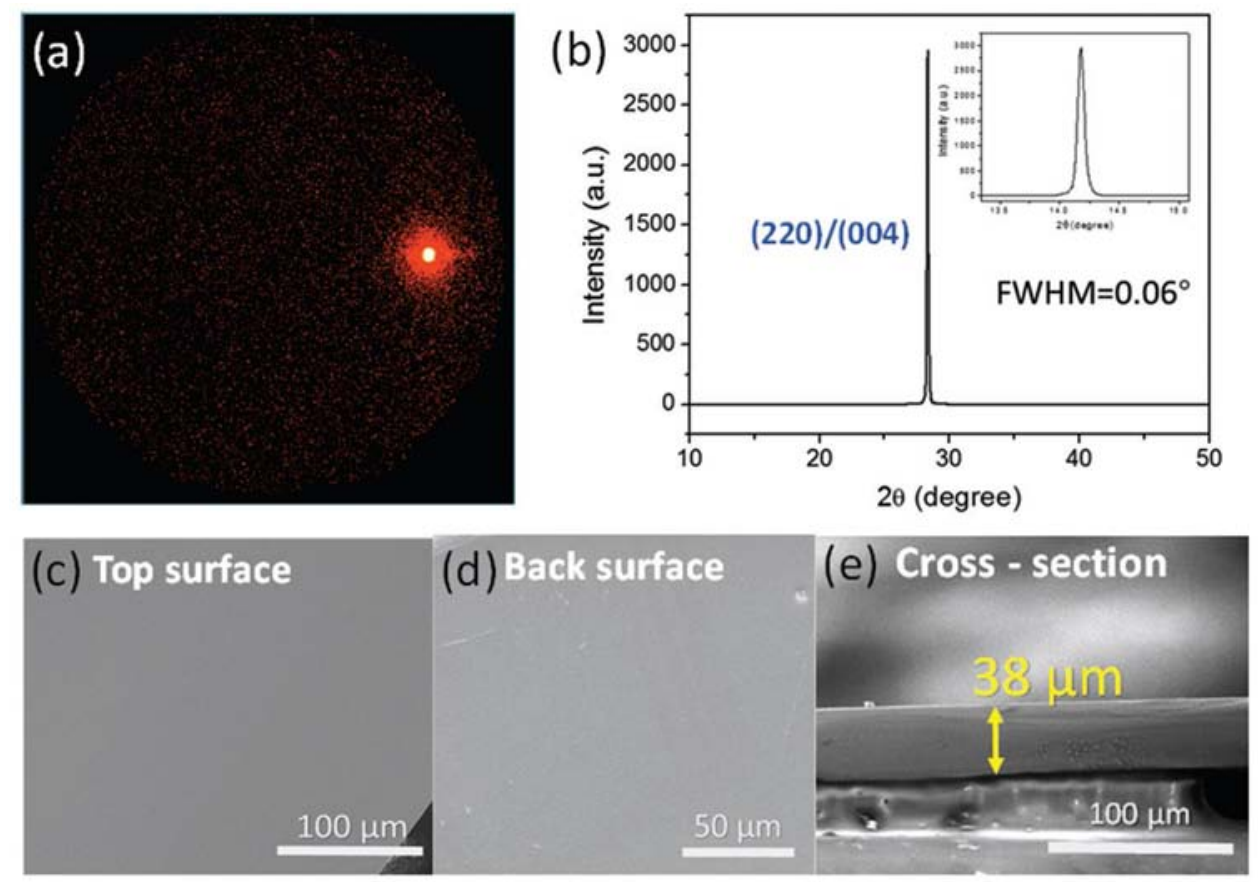

Figure 2. a) XRD detector image of $\mathrm{MAPbl}_{3}$ single-crystal wafer by the $2 \mathrm{D}$ detector. b) XRD pattern of crystal wafer recorded by $\mathrm{Cu} \mathrm{K} \alpha$ radiation. c-e) SEM images of top surface, backside surface, and cross-section of $\mathrm{MAPbl}_{3}$ single-crystal wafer. 
The absorption spectrum of the MAPbI3 crystal wafer with thickness of $100 \mu \mathrm{m}$ is shown in Figure 3a, which exhibit an obvious red-shift of the absorption edge by about $50 \mathrm{~nm}$ in comparison to the $1 \mu \mathrm{m}$ thick polycrystalline thin film fabricated by one-step method. [27] The red-shift of the absorption edge in MAPbI3 single crystal compared to the thin film is not caused by the band gap change of the single crystal, as evidenced by the similar photoluminescence $(\mathrm{PL})$ peak position of the single crystal (Figure 3a) with that of thin film reported previously. [4] Our recent study demonstrated that the band edge red-shift of single crystal is actually originated from utilization of the relatively weak absorption of below-gap transition in $\mathrm{MAPbl}_{3}$ [2]. This could effectively increase the total absorption of the solar spectrum, which is favorable for realizing a higher short-circuit current of the solar cells made from it.

We measured the charge recombination lifetime of MAPbI3 crystal wafer by time-resolved PL (TRPL) to find out the surface quality of the single crystals, [28] using a $404 \mathrm{~nm}$ pulsed diode laser as the excitation light with a pulse width of $45 \mathrm{ps}$. The measured charge recombination lifetime could be dominated by the charge recombination process at the crystal surface, due to the penetration length of about $50 \mathrm{~nm}$ for the $404 \mathrm{~nm}$ light. [29] Comparing the decay times derived from fitting a biexponential function to the TRPL measurements in Figure 3b, crystals of same thickness grown on solution surface show lifetimes of $\tau_{1}=59 \mathrm{~ns}$ and $\tau_{2}=324 \mathrm{~ns}$, dramatically longer than the thin single crystal grown on substrate $\left(\tau_{1}=9.6 n s, \tau_{2}=103\right.$ ns). [2] This indicates the higher surface quality of crystals grown using the

(a)

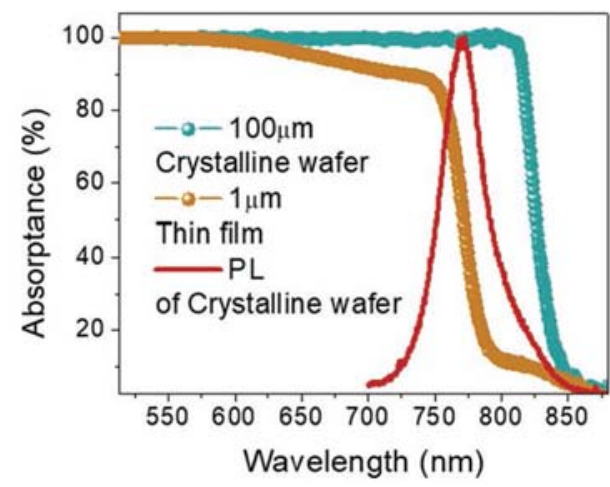

(b)

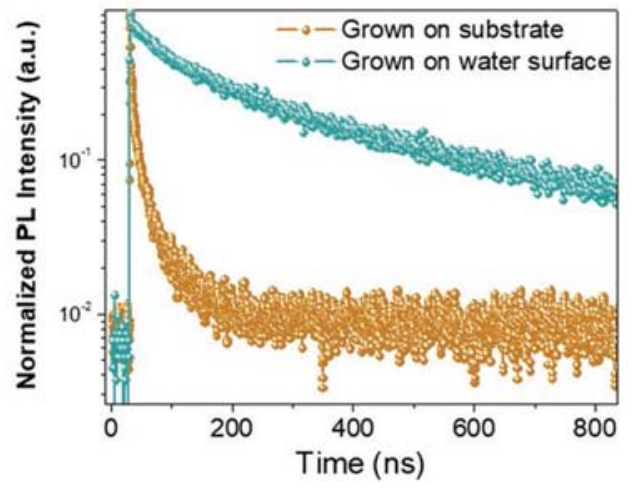

Figure 3. a) Absorption comparison of $100 \mu \mathrm{m}$ thickness $\mathrm{MAPbl}_{3}$ crystal wafer and $1 \mu \mathrm{m} \mathrm{MAPbl}{ }_{3}$ polycrystalline thin film by one-step method, and PL spectra of crystal wafer. b) The comparison of TRPL measurement of thin $\mathrm{MAPbl}_{3}$ crystal grown on substrate and grown on water surface with the same crystal thickness of about $30 \mu \mathrm{m}$. [2] 
solution surface method. Such a relatively long charge recombination lifetime combined with broader absorption and high crystallinity makes the $\mathrm{MAPbl}_{3}$ crystal wafer grown in this method suitable for fabricating a singlecrystal solar cell device.

As mentioned above, the co-planar lateral-structure solar cell is promising in achieving record high PCE, and we previously demonstrated the first co-planar lateral-structure perovskite single-crystal solar cell by piezoelectric poling process in which the $\mathrm{p}$ and $\mathrm{n}$ regions were generated by the ion migration through poling, causing domain boundaries, and the accumulation of them underneath the electrode. However, the poling process causes a small amount of damage to the crystals, which limited the device performance. [26] In addition, the doping caused by ion migration is not stable over the long term due to the ion back diffusion process. To address this problem, we fabricated the lateral-structure solar cell device by introducing electron transport layer without resorting to the poling process. $[25,26]$ The device structure and device fabrication process are illustrated in Figure 4a. First, a gold ( $\mathrm{Au}$ ) electrode (50 $\mathrm{nm}$ thick) was thermally evaporated on top of a crystal with the shape shown in Figure $4 a$ defined by a shadow mask. Subsequently, $20 \mathrm{~nm}$ thick fullerene (C60) and $8 \mathrm{~nm}$ thick 2,9-dimethyl-4,7diphenyl-1,10-phenanthroline (BCP) were deposited on the whole surface of the crystal. After thermal deposition of two Au electrodes by using designed mask, the area between two electrodes was the final device working area of $0.0364 \mathrm{~mm}^{2}$ shown in Figure 4a, and the device structure is $\mathrm{Au}$ / $\mathrm{MAPbl}_{3} / \mathrm{C60} / \mathrm{BCP} / \mathrm{Au}$. The MAPbI3 lateral-structure single-crystalline device was measured in the probe station under white illumination with an intensity

(a)

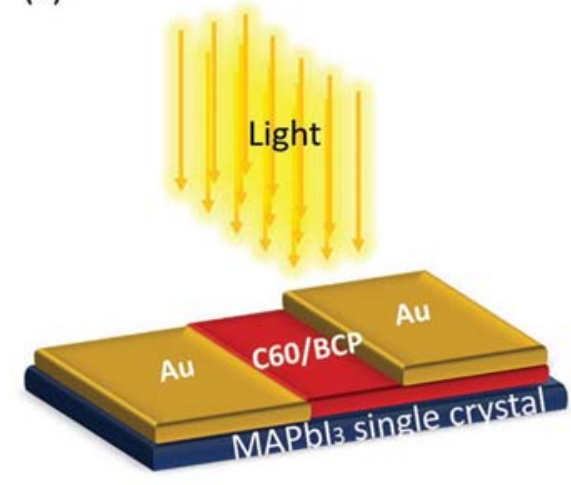

(b)

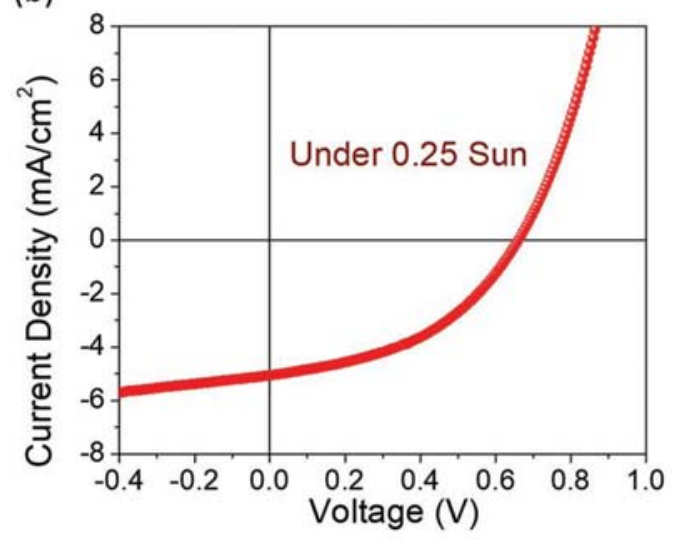

Figure 4. a) Scheme of $\mathrm{MAPbl}_{3}$ crystal-wafer lateral-structure solar cell device. b) The $J-V$ curve of our best co-planar lateral $\mathrm{MAPbl}_{3}$ single-crystal solar cell device with PCE of $5.9 \%$. 
of $25 \mathrm{~mW} \mathrm{~cm}^{-2}$ (0.25 sun) with photomask covered all exposed crystal surface except working area. We noticed this is important so that the efficiency can be accurately measured particularly in lateral-structure devices, because the very long carrier diffusion length in the single crystals may cause overrated short circuit current density if a photomask is absent. Figure $4 b$ shows the current density-voltage $(J-V)$ curve of a champion device with the short circuit current density $\left(J_{\mathrm{sc}}\right)$ of $5.06 \mathrm{~mA} \mathrm{~cm}{ }^{-2}$, open-circuit voltage $\left(V_{\text {oc }}\right)$ of $0.66 \mathrm{~V}$, Fill Factor (FF) of 0.44 under 0.25 sun light, which gave a PCE of $5.9 \%$. Compared with our reported lateral-structure device formed by poling, the dramatically increased $J_{s c}$ and FF resulted in a more than doubled PCE. This is the highest OIHP lateral-structure device performance that has been reported up to now. The current device efficiency is still much lower than the vertical-structure perovskite thin film solar cells. One possible reason is that the surface and interfacial charge recombination is still limiting the device efficiency. Therefore, many efforts of defect and trap passivation [27,30,31] which have been done in OIHP-based thin film device, could give inspiration to the $\mathrm{MAPbl}_{3}$ single-crystal lateral-structure device. Besides, the hole transport layer needs to be introduced to improve the hole carrier extraction and hence the device efficiency.

\section{Conclusion}

In conclusion, we developed a thin OIHP single-crystal growth method by introducing a driving force by solvent evaporation, and then $\mathrm{MAPbl}_{3}$ single-crystal wafer with lateral size of centimeters and thickness of tens of micrometers could be grown within $30 \mathrm{~min}$. The single-crystal nature of the wafer was confirmed by the XRD and SEM measurements. Moreover, the long charge recombination lifetime based on the TRPL measurement indicates the better crystal surface quality grown on solution surface than the thin single crystal grown directly on substrates by previously reported methods. Thus, in this growth method, the lateral-structure OHIP single-crystal solar cell devices achieved record PCE up to $5.9 \%$ without poling treatment.

\section{Experimental Section}

Precursor Solution and Growth of $\mathrm{MAPbl}_{3}$ Crystal Wafer: The precursor solution for growth was prepared similar to the previous method with modification. [4] Lead(II) acetate trihydrate (99\%) and hydriodic acid ( $\mathrm{HI}, 57 \% \mathrm{w} / \mathrm{w}$ aq. soln.) and methylamine $\left(\mathrm{CH}_{3} \mathrm{NH}_{2}\right)(40 \% \mathrm{w} / \mathrm{w}$ aq. soln.) were all purchased from Alfa Aesar. At first, $\mathrm{Pb}\left(\mathrm{OOCCH}_{3}\right)_{2} \cdot 3 \mathrm{H}_{2} \mathrm{O}(11.72 \mathrm{~g})$ powder was dissolved 
in $48 \mathrm{~mL}$ of $\mathrm{HI}$ acid solution in a $100 \mathrm{~mL}$ beaker and put on the top of hotplate at $100{ }^{\circ} \mathrm{C}$ to get clear mixed acid solution. Then $2.66 \mathrm{~mL}$ of methylamine aqueous solution was added into the beaker and stirred until fully dissolved. The temperature of hotplate was slowly decreased to $90{ }^{\circ} \mathrm{C}$ and the beaker was covered by glass with controllable gap for adjustable evaporation rate of solutions. The crystal was nucleated and then grew larger on the top surface of the solution. After nucleus was formed and started floating on top surface of solution, the $\mathrm{MAPbl}_{3}$ seed crystals were also started to grow larger to $1-1.5 \mathrm{~cm}$ length in less than $30 \mathrm{~min}$. As shown in Figure 1a, the crystals could float on the solution surface due to the three forces including gravity, buoyancy, and surface tension. Since the crystals could stay still on surface, the equilibrium equation was illustrated from classic fluid mechanics as shown below

$$
G=F_{\mathrm{b}}+F_{\mathrm{s}} \cdot \cos \theta
$$

For the $F_{\mathrm{b}}$ buoyancy, it was only determined by the volume of the displaced body of liquid, which was relative to the density difference between crystal $\left(4.12 \mathrm{~g} \mathrm{~mL}^{-1}\right)$ and solution $\left(1.17 \mathrm{~g} \mathrm{~mL}^{-1}\right)$. The crystal could float on the solution surface with the support of $F_{\mathrm{b}}$ and $F_{s^{\prime}}$ due to the crystal symmetry of large $L / T$ ratio (length to thickness) and contact angles at the crystal-solution-air interfaces. Finally, the crystal wafers were transferred and dried out from the solution surface after they were large enough for device.

Fabrication of Lateral-Structure $\mathrm{MAPb}_{3}$ Single-Crystal Device: For the holefree lateral $\mathrm{MAPbl}_{3}$ single-crystal solar cell device fabrication, a $50 \mathrm{~nm} \mathrm{Au}$ was thermal deposited on top of half part of the crystal wafer surface as one electrode. Then the Au area was covered and the other layers of $20 \mathrm{~nm} \mathrm{C_{60 }}$ and $8 \mathrm{~nm} \mathrm{BCP}$ were deposited on the other part of the wafer surface. After the deposition, a gap width of $50 \mathrm{um}$ and length of $1 \mathrm{~mm}$ shadow mask was covered on the interfacial edge of these two areas. Another $50 \mathrm{~nm}$ Au was thermal deposited on the top surface as the other electrode.

Current Density-Voltage (J-V) Measurement of Device: Two probes were used to contact each electrode on top surface of the device, and the device was measured under white illumination with an intensity of $25 \mathrm{~mW} \mathrm{~cm}^{-2}(0.25$ sun) in vacuum with photomask covering all the exposed crystal surface except the working area. The photocurrent density-voltage curves of lateral $\mathrm{MAPbl}_{3}$ single-crystal solar cell devices were measured by a Keithley 2400 source meter.

Material and Device Characterization: XRD spectra were measured by the Bruker-AXS D8 Discover Diffractometer equipped with the high-sensitivity 
2D Vantec 500 area detector. Bruker D8 Discover diffractometer was configured in parallel beam geometry with $\mathrm{Cu}$ K $\alpha$ radiation (wavelength of 1.5418 $\AA$ ). Top and bottom view and cross-section SEM images were obtained with a Quanta 200 FEG ESEM. Absorption spectra were measured by a LAMBDA 1050 UV-vis-NIR (near infra-red) Spectrophotometer. The PL spectrum was measured by iHR320 Photoluminescence Spectroscopy at room temperature. A $532 \mathrm{~nm}$ green laser with an intensity of $10 \mathrm{~mW} \mathrm{~cm}^{-2}$ from Laser glow Technologies was used as the excitation source in PL measurement. The TRPL was measured with a Horiba Delta Pro time-correlated single photon counting system, and the $404 \mathrm{~nm}$ pulsed laser diode with pulse width of 45 ps was used as the excitation source. The scattered laser was eliminated with a $770 \mathrm{~nm}$ band-pass filter.

\section{Supporting Information follows the References.}

Acknowledgments - Y.L. and Q.D. contributed equally to this work. This work is financially supported by National Science Foundation under award ECCS- 1747660. The authors declare no conflict of interest.

\section{References}

1. J. Huang, Y. Shao, Q. Dong, J. Phys. Chem. Lett. 2015, 6, 3218.

2. Z. Chen, Q. Dong, Y. Liu, C. Bao, Y. Fang, Y. Lin, S. Tang, Q. Wang, X. Xiao, Y. Bai, Nat. Commun. 2017, 8, 1890.

3. S. D. Stranks, G. E. Eperon, G. Grancini, C. Menelaou, M. J. Alcocer, T. Leijtens, L. M. Herz, A. Petrozza, H. f. J. Snaith, Science 2013, 342, 341.

4. Q. Dong, Y. Fang, Y. Shao, P. Mulligan, J. Qiu, L. Cao, J. Huang, Science 2015, 347, 967.

5. D. Shi, V. Adinolfi, R. Comin, M. Yuan, E. Alarousu, A. Buin, Y. Chen, S. Hoogland, A. Rothenberger, K. Katsiev, Science 2015, 347, 519.

6. Y. Shao, Y. Fang, T. Li, Q. Wang, Q. Dong, Y. Deng, Y. Yuan, H. Wei, M. Wang, A. Gruverman, Energy Environ. Sci. 2016, 9, 1752.

7. W. Nie, H. Tsai, R. Asadpour, J.-C. Blancon, A. J. Neukirch, G. Gupta, J. J. Crochet, M. Chhowalla, S. Tretiak, M. A. Alam, Science 2015, 347, 522.

8. G. J. A. Wetzelaer, M. Scheepers, A. M. Sempere, C. Momblona, J. Ávila, H. J. Bolink, Adv. Mater. 2015, 27, 1837.

9. K. Yoshikawa, H. Kawasaki, W. Yoshida, T. Irie, K. Konishi, K. Nakano, T. Uto, D. Adachi, M. Kanematsu, H. Uzu, Nat. Energy 2017, 2, 17032.

10. B. Azzopardi, C. J. Emmott, A. Urbina, F. C. Krebs, J. Mutale, J. Nelson, Energy Environ. Sci. 2011, 4, 3741.

11. P.-J. Ribeyron, Nat. Energy 2017, 2, 17067. 
12. Y. Dang, Y. Liu, Y. Sun, D. Yuan, X. Liu, W. Lu, G. Liu, H. Xia, X. Tao, CrystEngComm 2015, 17, 665.

13. T. Baikie, Y. Fang, J. M. Kadro, M. Schreyer, F. Wei, S. G. Mhaisalkar, M. Graetzel, T. J. White, J. Mater. Chem. A 2013, 1, 5628.

14. Z. Lian, Q. Yan, T. Gao, J. Ding, Q. Lv, C. Ning, Q. Li, J.-I. Sun, J. Am. Chem. Soc. 2016, 138, 9409.

15. M. I. Saidaminov, A. L. Abdelhady, B. Murali, E. Alarousu, V. M. Burlakov, W. Peng, I. Dursun, L. Wang, Y. He, G. Maculan, Nat. Commun. 2015, 6, 7586.

16. Y. Liu, Z. Yang, D. Cui, X. Ren, J. Sun, X. Liu, J. Zhang, Q. Wei, H. Fan, F. Yu, Adv. Mater. 2015, 27, 5176.

17. Y. Liu, J. Sun, Z. Yang, D. Yang, X. Ren, H. Xu, Z. Yang, S. F. Liu, Adv. Opt. Mater. 2016, 4, 1829.

18. Y. Liu, Y. Zhang, Z. Yang, D. Yang, X. Ren, L. Pang, S. F. Liu, Adv. Mater. 2016, $28,9204$.

19. Y.-X. Chen, Q.-Q. Ge, Y. Shi, J. Liu, D.-J. Xue, J.-Y. Ma, J. Ding, H.-J. Yan, J.-S. Hu, L.-J. Wan, J. Am. Chem. Soc. 2016, 138, 16196.

20. A. A. Zhumekenov, V. M. Burlakov, M. I. Saidaminov, A. Alofi, M. A. Haque, B. Turedi, B. Davaasuren, I. Dursun, N. Cho, A. M. El-Zohry, ACS Energy Lett. 2017, 2, 1782.

21. T. Ye, X. Wang, X. Li, A. Q. Yan, S. Ramakrishna, J. Xu, J. Mater. Chem. C 2017, 5, 1255.

22. Z. Yang, Y. Deng, X. Zhang, S. Wang, H. Chen, S. Yang, J. Khurgin, N. X. Fang, X. Zhang, R. Ma, Adv. Mater. 2018, 30, 1704333.

23. W. Peng, L. Wang, B. Murali, K. T. Ho, A. Bera, N. Cho, C. F. Kang, V. M. Burlakov, J. Pan, L. Sinatra, Adv. Mater. 2016, 28, 3383.

24. H.-S. Rao, B.-X. Chen, X.-D. Wang, D.-B. Kuang, C.-Y. Su, Chem. Commun. 2017, 53, 5163.

25. L. Lee, J. Baek, K. S. Park, Y. Lee, N. K. Shrestha, M. M. Sung, Nat. Commun. 2017, 8, 15882.

26. Q. Dong, J. Song, Y. Fang, Y. Shao, S. Ducharme, J. Huang, Adv. Mater. 2016, 28, 2816.

27. X. Zheng, B. Chen, J. Dai, Y. Fang, Y. Bai, Y. Lin, H. Wei, X. C. Zeng, J. Huang, Nat. Energy 2017, 2, 17102.

28. W. Wei, Y. Zhang, Q. Xu, H. Wei, Y. Fang, Q. Wang, Y. Deng, T. Li, A. Gruverman, L. Cao, Nat. Photonics 2017, 11, 315.

29. H. Wei, Y. Fang, P. Mulligan, W. Chuirazzi, H.-H. Fang, C. Wang, B. R. Ecker, Y. Gao, M. A. Loi, L. Cao, Nat. Photonics 2016, 10, 333.

30. Y. Shao, Z. Xiao, C. Bi, Y. Yuan, J. Huang, Nat. Commun. 2014, 5, 5784.

31. Q. Chen, H. Zhou, T.-B. Song, S. Luo, Z. Hong, H.-S. Duan, L. Dou, Y. Liu, Y. Yang, Nano Lett. 2014, 14, 4158. 


\title{
SUPPLEMENTARY INFORMATION
}

\section{Fast growth of thin MAPbI3 crystal wafers on aqueous solution surface for efficient lateral-structure perovskite solar cells}

\author{
Ye Liu ${ }^{\dagger 1,2}$, Qingfeng Dong ${ }^{\dagger 1}$, Yanjun Fang ${ }^{1}$, Yuze Lin $^{2}$, Yehao Deng ${ }^{2}$, Jinsong Huang ${ }^{1,2} *$
}

${ }^{1}$ Department of Mechanical and Materials Engineering, University of Nebraska-Lincoln, Lincoln, Nebraska 68588, USA.

${ }^{2}$ Department of Applied Physical Sciences, University of North Carolina, Chapel Hill, NC 27599, USA

${ }^{5}$ These authors contributed equally

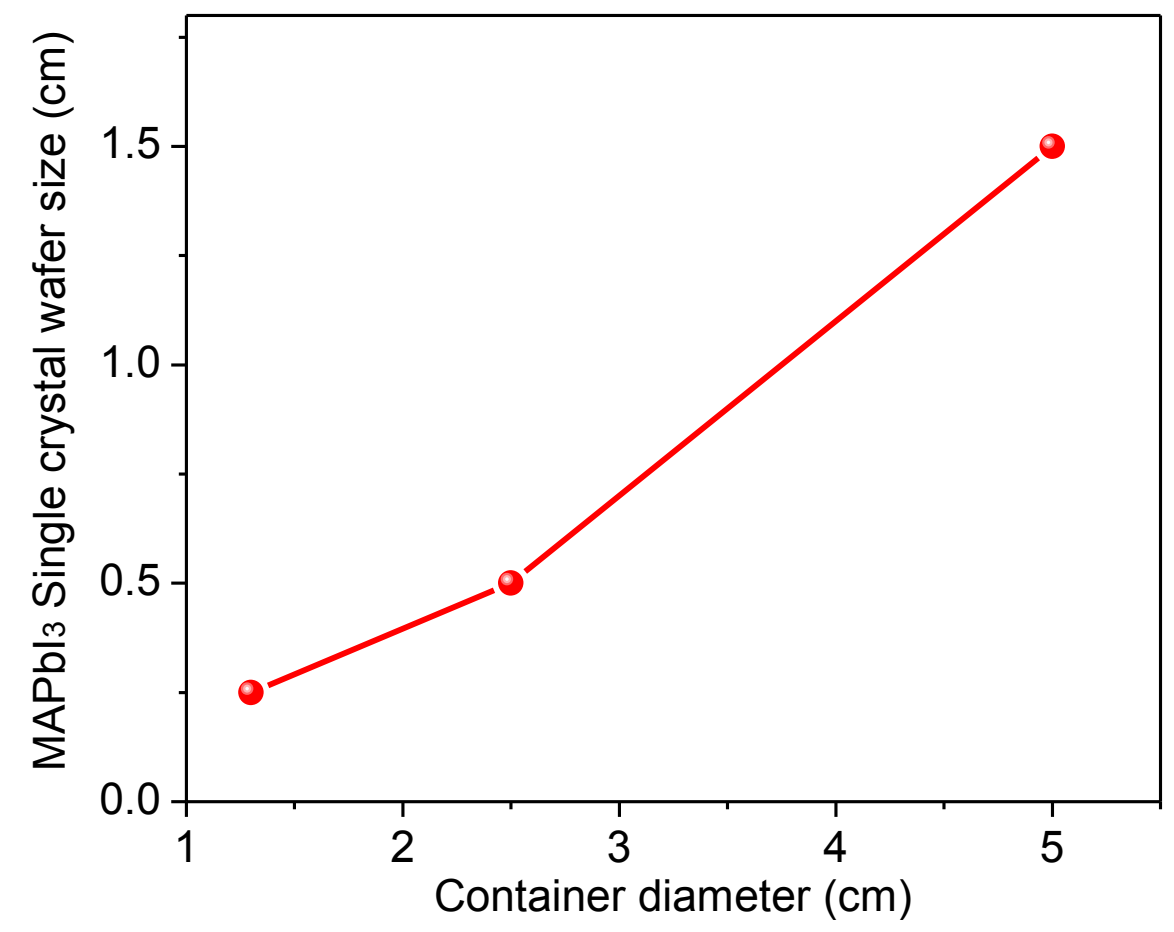

Figure S1. The correlation plot of $\mathrm{MAPbI}_{3}$ single crystal wafer size and container diameter size.

\footnotetext{
* Correspondence to JH, Email: jhuang@unc.edu.
} 